\title{
SISTEM INFORMASI DETEKSI KEHADIRAN DAN MEDIA PENYAMPAIAN PENGUMUMAN DOSEN DENGAN MENGGUNAKAN TEKNIK PENGENALAN QR CODE
}

\author{
O.K Saddam Hussein ${ }^{1)}$ Refni Wahyuni ${ }^{2)}$ Yuda Irawan ${ }^{3)}$ Harun Mukhtar ${ }^{4)}$ \\ 1,4) Teknik Informatika Universitas Muhammadiyah Riau \\ 2,3) Teknik Informatika STMIK Hang Tuah Pekanbaru \\ 1,4) Jl. K.H. Ahmad Dahlan No. 88, Pekanbaru 28000 Indonesia \\ 2,3) Jl. Mustafa Sari No 5 Tangkerang Selatan, Pekanbaru 28288 Indonesia \\ E-Mail:oksaddam@student.umri.ac.id,refniabid@gmail.com,yudairawan89@gmail.com, \\ harunmukhtar@umri.ac.id
}

\begin{abstract}
ABSTRAK
Sistem Informasi Deteksi Kehadiran Dan Media Penyampaian Pengumuman Dosen Dengan Menggunakan Teknik Pengenalan QR Code" adalah aplikasi yang berfungsi untuk mendukung proses penyebaran informasi di kampus Universitas Muhammadiyah Riau sehingga menjadi lebih efektif dan efisien serta mempermudah mahasiswa dalam mendapatkan informasi. Aplikasi ini dapat digunakan oleh Dosen dan Mahasiswa sebagai penerima informasi. Hasil dari penelitian ini merupakan sebuah aplikasi berbasis web yang dapat mendukung proses penyebaran informasi di kampus Universitas Muhammadiyah Riau. Penelitian ini dibangun menggunakan metode pengembangan perangkat lunak Waterfall, menggunakan UML untuk mendokumentasikan, menspesifikasikan, dan memodelkan sistem. Diimplementasikan menggunakan bahasa pemrograman PHP dengan menggunakan Framework Laravel serta menggunakan database MySQL dan software pendukung lainnya.

Kata Kunci: Web, Framework, Laravel, PHP, MySQL

ABSTRACT

Information Systems of Attendance Detection and Media Submission of Lecturer Announcement by Using Engineering Introduction $Q R$ Code "is an application that serves to support the process of disseminating information on the campus of Muhammadiyah University of Riau to become more effective and efficient and facilitate students in obtaining information. This application can be used by Lecturers and Students as recipient of information. The results of this study is a web-based application that can support the process of disseminating information on the campus of the University of Muhammadiyah Riau. The research was built using the Waterfall software development method, using UML to document, specify, and model the system. Implemented using PHP programming language using Laravel Framework and using MySQL database and other supporting software.
\end{abstract}

Keywords: Web, Framework, Laravel, PHP, MySQL

\section{PENDAHULUAN}

Mendapatkan kemudahan dalam memperoleh informasi merupakan hak bagi setiap mahasiswa, namun terkadang kesusahan dalam mendapat informasi dengan pasti apakah dosen hadir atau tidak. Proses penyampaian informasi yang dilakukan dosen biasanya dengan cara mengirim pesan atau menel-phone petugas tata usaha (TU) yang kemudian petugas tata usaha membuat tulisan di kertas dan ditempelkan didepan ruang tata usaha. Penyebaran informasi melalui media kertas sepertinya kurang tepat. Selain proses penyebarannya yang membutuhkan waktu, kurangnya tempat untuk menempelkan kertas juga menjadi hambatan dalam penyebaran informasi. Akibatnya, informasi-informasi yang penting tidak sepenuhnya tersampaikan.

Dengan adanya sistem Informasi Deteksi Kehadiran Dan Media Penyampaian 
Pengumuman Dosen Dengan Menggunakan Teknik Pengenalan $Q R$ Code, diharapkan dapat membantu dosen dalam proses penyebaran informasi di lingkungan Prodi Teknik Informatika Universitas Muhammadiyah Riau. Dengan adanya sistem ini diharapkan dosen tidak perlu menyampaikan informasi dengan media kertas, telphone dan sms. Tetapi informasi tersebut dapat dilihat langsung dengan media layar digital di prodi teknik informatikan. Selanjutnya mahasiswa juga tidak perlu hadir ke kampus dan bertanya ketata usaha mengenai informasi kehadiran dosen, namun informasi tersebut dapat di akses melalui website yang akan di bangun.

\section{Rumusan Masalah}

1. Bagaimana Penerapan sistem Informasi Deteksi Kehadiran Dan Media Penyampaian

Pengumuman Dosen Dengan

Menggunakan Teknik Pengenalan $Q R$ Code di Prodi Teknik Informatika Universitas Muhammadiyah Riau.

2. Bagaimana agar memudahkan dosen memberikan informasi kehadiran, pembatalan kuliah atau jam kuliah tambahan kepada mahasiswa di prodi teknik informatika Universitas Muhammadiyah Riau.

3. Bagaimana sistem tersebut dapat menyimpan dan menampilkan data kehadiran dosen dan informasi lain nya.

\section{Tujuan}

1. Dengan adanya sistem ini dosen lebih mudah menyampaikan informasi kepada mahasiswa.
2. Dapat menampilkan informasi yang mudah diakses oleh mahasiswa dimanapun dan kapanpun secara online.

3. Dengan adanya sistem ini informasi dapat tersimpan dengan baik.

\section{Manfaat}

1. Memberikan informasi yang lebih akurat.

2. Mempermudah dosen dan bagian tata usaha dalam menyampaikan informasi.

3. Mempermudah mahasiswa dalam mendapatkan informasi.

Pada subbab ini akan membahas tentang tinjauan Sistem Informasi, Android, Android studio, Java Development Kit (JDK), PHP. Mysql. UML (Unified Modelling Language),

\section{Sistem Informasi}

Menurut Iriani S, Dwi Priyani (2013) Sistem informasi adalah kombinasi dari teknologi informasi dan aktivitas orang yang menggunakan teknologi itu untuk mendukung operasi dan manajemen. Dalam arti yang sangat luas, istilah sistem informasi yang sering digunakan merujuk kepada interaksi antara orang, proses algoritmik, data, dan teknologi.

\section{Android}

Menurut Andi juansyah, 2016 Android adalah sebuah sistem operasi perangkat mobile berbasis linux yang mencangkup sistem operasi, middleware dan aplikasi. Android menyediakan platform terbuka bagi para pengembang untuk menciptakan aplikasi mereka. Awalnya, Google Inc. membeli Android Inc. yang merupakan pendatang baru yang membuat peranti lunak untuk ponsel atau smartphone. Kemudian untuk mengembangkan Android, dibentuklah Open Handset Alliance, konsorsium dari 34 
perusahaan peranti keras, peranti lunak dan telekomunikasi, termasuk Google, HTC, Intel, Motorola, Qualcomm, T-Mobile, dan Nvidia.

\section{Android studio}

Menurut Andi juansyah, 2016 Android studio adalah IDE (Integrated Development Environment) resmi untuk pengembangan aplikasi Android dan bersifat open source atau gratis. Peluncuran Android Studio ini diumumkan oleh Google pada 16 mei 2013 pada event Google I/O Conference untuk tahun 2013. Sejak saat itu, Android Studio mengantikan Eclipse sebagai IDE resmi untuk mengembangkan aplikasi Android.

\subsection{Java Development Kit (JDK)}

Andi juansyah, 2016 Java Development Kit (JDK) adalah sekumpulan perangkat lunak yang dapat kamu gunakan untuk mengembangkan perangkat lunak yang berbasis Java, sedangkan JRE adalah sebuah implementasi dari Java Virtual Machine yang benarbenar digunakan untuk menjalankan program java. Biasanya, setiap JDK berisi satu atau lebih JRE dan berbagai alat pengembangan lain seperti sumber compiler java, bundling, debuggers, development libraries dan lain sebagainya.

\section{PHP}

Widianti Utami Dwi 2012 PHP merupakan bahasa pemrogramana untuk script web server-side. Bahasa pemrograman PHP diciptakan pertama kali oleh Rasmus Lerdorf, seorang pemrogram $\mathrm{C}$ yang sangat handal. Semula PHP hanya digunakan untuk mencatat seberapa jumlah pengunjung pada hompage-nya. Rasmus adalah salah seorang pendukung open source. Karen itulah ia mengeluarkan Personal Home Page Tools versi 1.0 secara gratis atau freeware pada tahun 1995. PHP memiliki beberapa kelebihan yang tidak dimiliki oleh bahasa-bahasa sejenisnya, yaitu:

1) Bahasa pemrograman PHP adalah sebuah bahasa script yang tidak melakukan sebuah kompilasi dalam penggunaanya.

2) Web Server yang mendukung PHP dapat ditemukan dimana - mana dari mulai IIS sampai dengan apache, dengan configurasi yang relatif

3) Dalam sisi pengembangan lebih mudah, karena banyaknya milis - milis dan developer yang siap membantu dalam pengembangan.

4) Dalam sisi pemahamanan, PHP adalah bahasa scripting yang paling mudah karena referensi yang banyak.

5) PHP adalah bahasa open source yang dapat digunakan di berbagai mesin (linux, unix, windows) dan dapat dijalankan secara runtime melalui console serta juga dapat menjalankan perintah-perintah sistem.

\section{MySQL}

Dwi Priyanti, S.I 2013 MySQL sebenarnya merupakan turunan salah satu konsep utama dalam basis data yang telah ada sebelumnya; SQL (Structured Query Language). SQL adalah sebuah konsep pengopeasian basisdata, terutama untuk pemilihan atau seleksi dan pemasukan data yang memungkinkan pengoperasian data dikerjakan dengan mudah secara otomatis.

\section{XАMPP}

Dwi Priyanti, S.I 2013 XAMPP adalah perangkat lunak bebas, yang mendukung banyak system operasi, merupakan kompilasi dari beberapa program. Fungsinya adalah sebagai server yang berdiri sendiri (localhost), yang terdiri atas program Apache HTTP 
Server, MySQL database, dan penerjemah bahasa yang ditulis dengan bahasa pemrograman PHP dan Perl. Nama XAMP merupakan singkatan dari $\mathrm{X}$ (empat system operasi apapun), Apache, MySQL, PHP dan Perl. Program ini tersedia dalam GNU General Public License dan bebas, merupakan web server yang mudah digunakan yang dapat melayani tampilan halaman web yang dinamis.

\section{UML (Unified Modelling Language)}

Simaremare Yosua, 2015:471 UML merupakan bahasa visual dalam pemodelan yang memungkinkan pengembang sistem membuat sebuah blueprint yang dapat menggambarkan visi mereka tentang sebuah sistem dalam format yang standar, mudah dimengerti, dan menyediakan mekanisme untuk mudah dikomunikasikan dengan pihak lain.

\section{METODE}

Metode yang diterapkan oleh penulis dalam penelitian ini dengan menggunakan metode Development Life Cycle (SDLC). Yang menggunakan beberapa tahap dalam pengembangan sistem. tahap-tahap dalam pengembangan sistem sesuai dengan SDLC meliputi tahapan sebagai berikut pada Gambar 1.

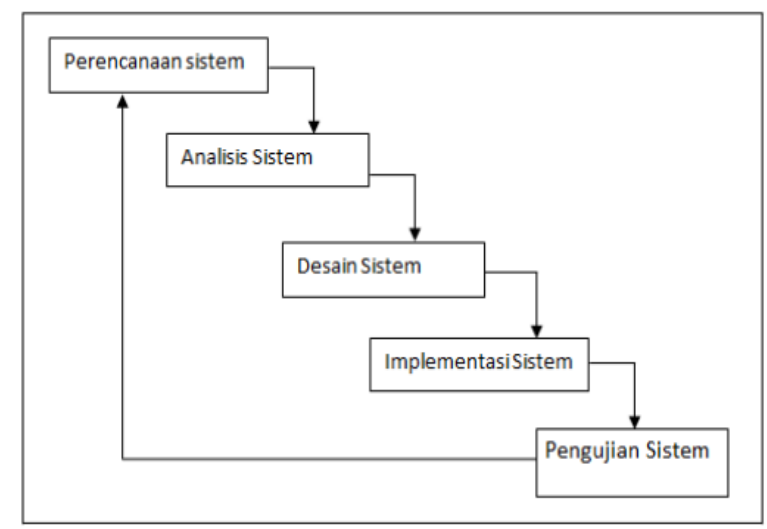

Gambar 1. Waterfall

\section{Perencanaan Sistem}

Kegiatan yang dilakukan pada tahap perencanaan sistem meliputi :

\section{Mendefinisikan Masalah}

Berdasarkan kegiatan yang telah dilakukan pada tahap perencanaan sistem, maka definisi permasalahan yaitu sulit nya bagi dosen untuk menyampaikan informasi kepada mahasiswa dan hilangnya informasi dengan menuliskan di atas kertas bisa menyebabkan miss komunikasi terhadap mahasiswa.

2. Menentukan tujuan sistem

Tujuan sistem baru ini adalah untuk mempermudah proses penyampaikan informasi kepada mahasiswa.

\section{Analisa sistem}

Analisis sistem yang dilakukan penulis penelitian ini adalah melakukan kegiatan analisa setelah data dari narasumber atau sumber data yang terkumpul. Menganalisis kebutuhan dari sisitem yang akan dibuat. Mengindentifikasi kebutuhan dari ststem yang akan dibuat dengan cara menetapkan data mana yang akan dipakai.

\section{Desain Sistem}

Pada tahapan ini hal yang dilakukan penulis adalah proses desain menggunakan Unified Modelling Language (UML).

\section{Implementasi Sistem}

Pada tahapan ini yang dikakukan oleh penulis adalah pengimplementasian desain sistem kedalam bahasa pemograman atau melakukan mengkodingan terhadap sistem yang akan di buat. Dalam hal ini penulis menggunakan perangkat pendukung berupa software dan hardware.

6. Tahap pengujian sistem 
Tahap pengujian ini adalah tahap dimana sistem akan diuji coba agar dapat diketahu kekurangannya serta untuk menentukan apakah sistem yang dibuat sudah sesuai dengan kebutuhan pengguna atau belum. Metode yang digunakan penulis dalam pengujian ini adalah Black Box Testing, pengujian dilakukan dengan mengamati hasil eksekusi melalui data uji dan memeriksa fungsional dari perangkat lunak.

\section{HASIL}

\section{Pemodelan Sistem}

Berikut ini adalah tahapan-tahapan yang akan penulis sajikan dengan pemodelan ini :

\section{Use Case Diagram Admin atau Tata Usaha}

Usecase diagram gambar 2 menjelaskan proses kerja Admin atau tata usaha dalam melakukan kegiatan pada sistem, setelah Login admin atau tata usaha dapat mengases sistem ini dapat menginput semua data yang ada di usecase master data dan dapat mengisi atau membuat pengumuman.

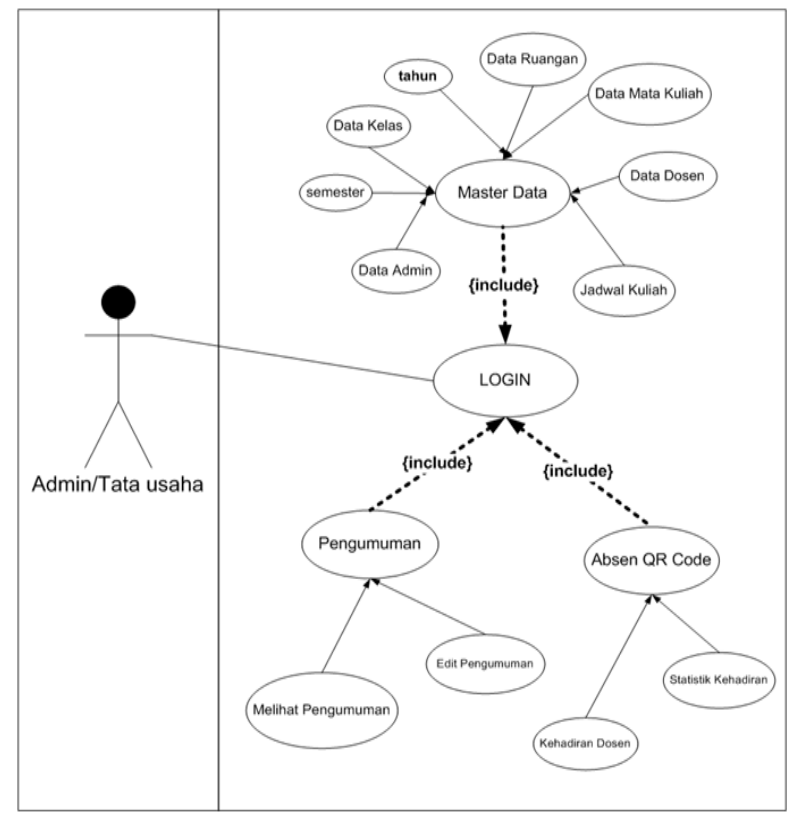

Gambar 2. Use Case Diagram Admin atau Tata Usaha

\section{Use Case Diagram Dosen}

Usecase diagram gambar 3 menjelaskan proses kerja Dosen dalam melakukan kegiatan pada sistem, setelah Login Dosen dapat mengases sistem ini dapat menginput data dosen, melihat jadwal, membuat pengumuman dan edit pengumunan.

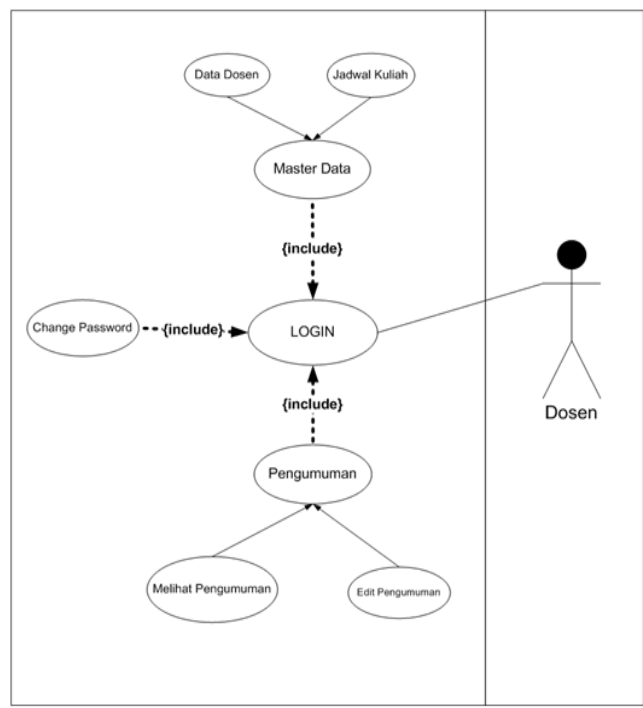

Gambar 3 .Use Case Diagram Dosen

\section{Use Case diagram Mahasiswa}

Usecase diagram gambar 4 menjelaskan proses kerja Mahasiswa dalam melakukan kegiatan pada sistem ini. Mahasiswa hanya dapat melihat pengumuman dan melihat kehadiran dosen.

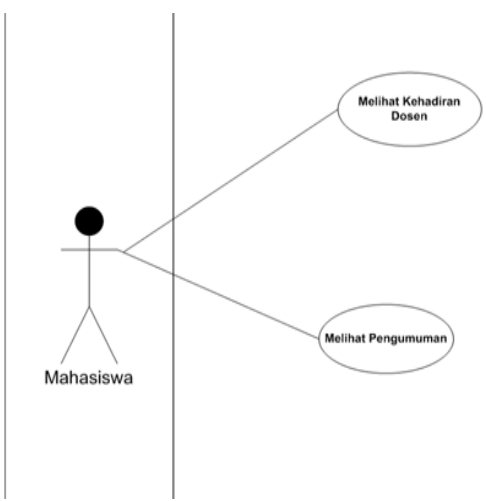

Gambar 4. Use Case Diagram Mahasiswa 


\section{Activity Diagram Admin}

Diagram aktivitas Admin merupakan aktivitas pengguna yang dalam hal ini adalah bagian tata usaha. admin dapat melakukan segala hal penginputan data di dalam sistem. Berikut gambar activity diagram admin.

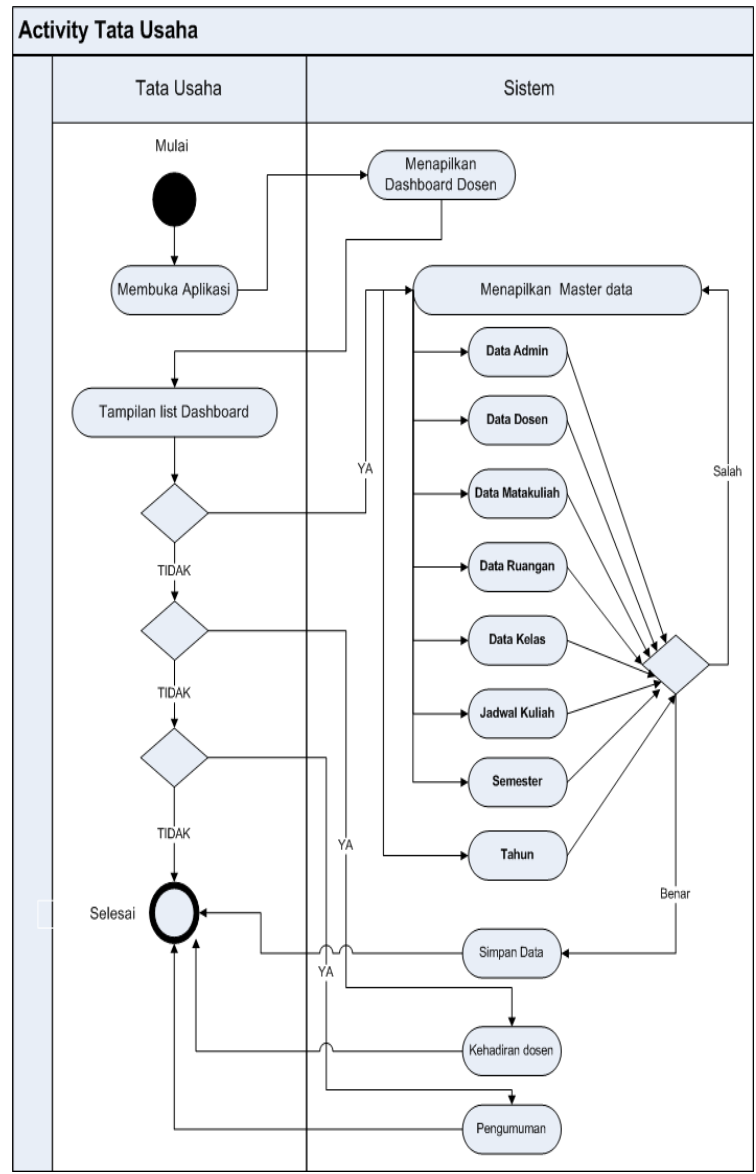

Gambar 5. Activity Diagram Admin

\section{Acrivity Diagram Dosen}

Diagram aktivitas Dosen merupakan aktivitas pengguna yang dalam hal ini adalah Dosen. Dosen dapat mengisi data diri melihat jadwal mengajaar dosen tersebut dan membuat pengumuman yang telah ditampilkan oleh sistem. Berikut gambar activity diagram mahasiswa, dapat dilihat

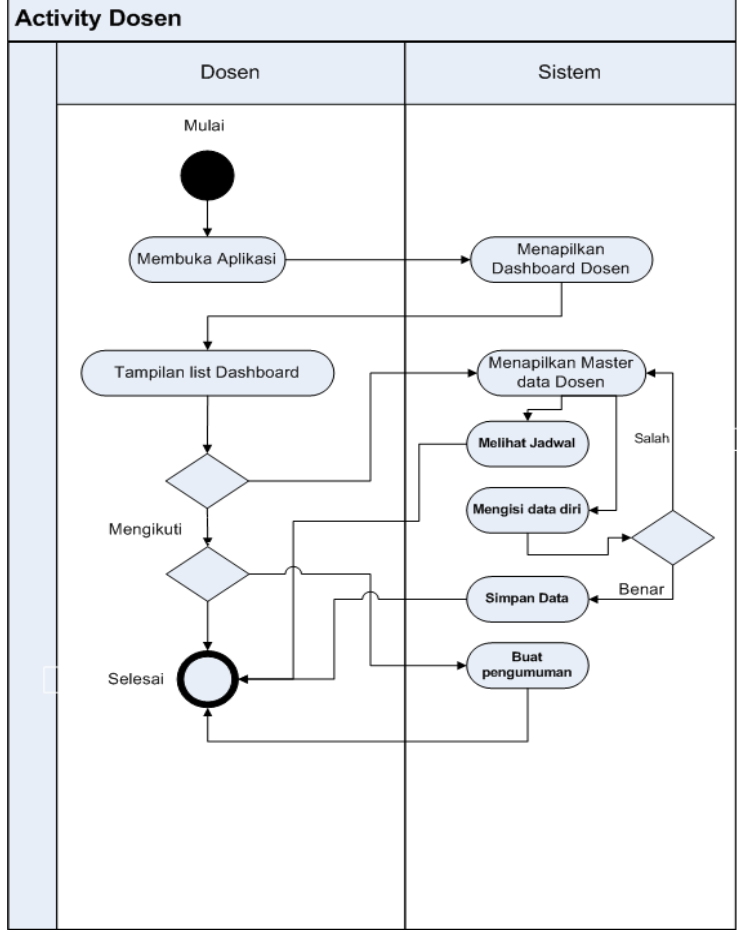

Gambar 6. Activity Diagram Dosen

\section{Class Diagram}

Class diagram yang digunakan untuk menampilkan beberapa kelas serta paketpaket yang ada dalam sistem yang sedang dikembangkan.

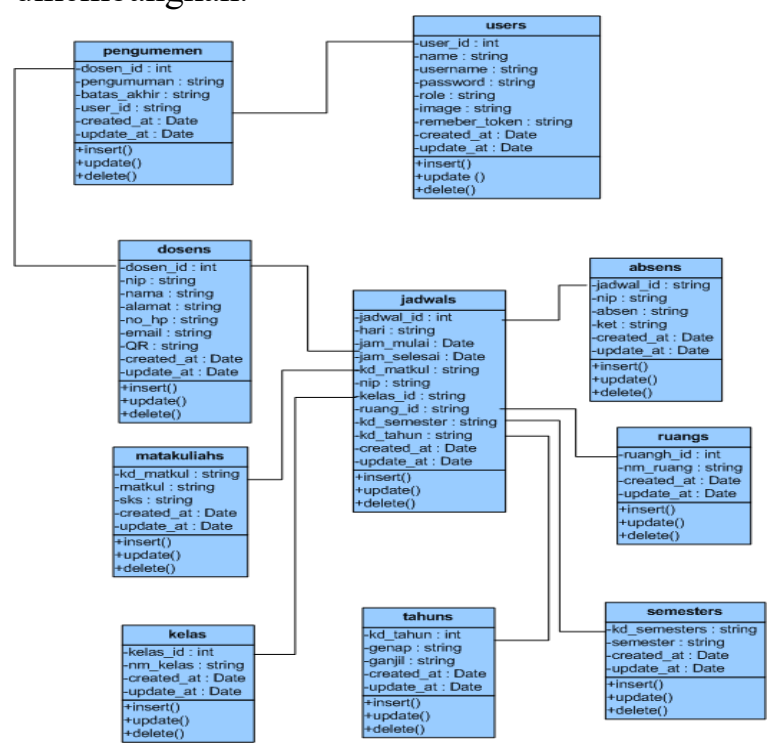

Gambar 7. Class Diagram Sistem informasi deteksi kehadiran dosen 


\section{Implementasi Sistem}

Setelah melakukan analisis terhadap sistem maka tahapan selanjutnya adalah implementasi sistem. Implementasi sistem informasi deteksi kehadiran dan media penyampaian pengumuman dosen.
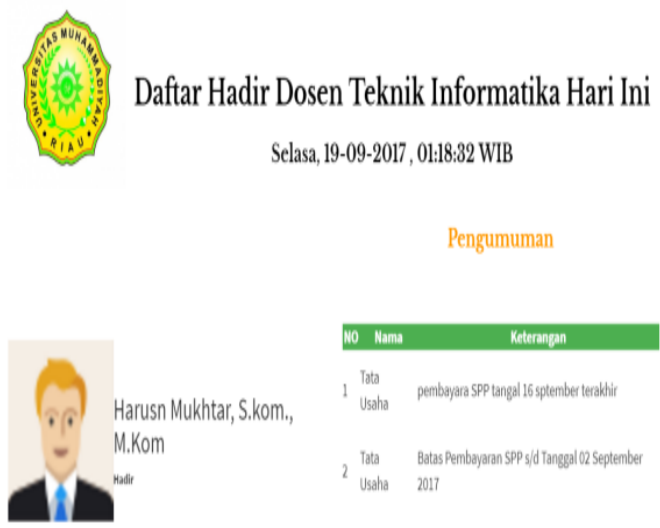

Gambar 8 Implementasi Tampilan desktop

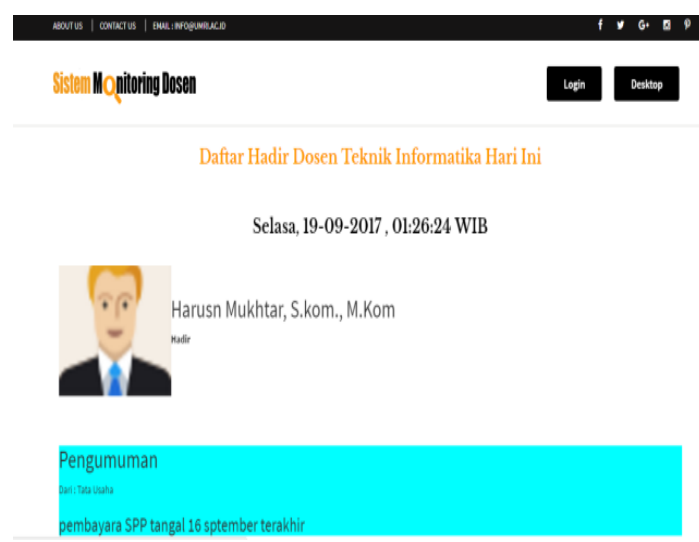

Gambar 9. Implementasi Tampilan Website

\section{Implementasi Menu Kehadiran dosen}

Menu kehadiran dosen, list data kehadiran dosen merupakan view nya, view ini di panggil dari controller kehadrian dosen pada fungsi detail kehadiran dosen, dari controller tersebut controller mengecek data ke dalam database, dengan menggunakan query pada model absen pada fungsi detail kehadiran dosen, jika data tersedia di database maka view akan menampilkan detail kehadiran dosen.

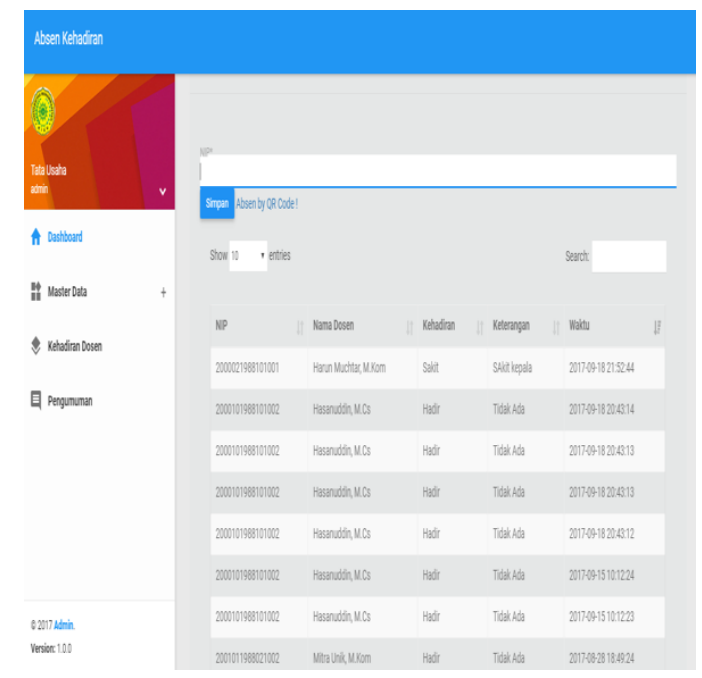

Gambar 10. Implementasi Kehadiran Dosen

\section{Implementasi Pengumuman}

Pada menu pengumuman, form input pengumuman merupakan view nya, view ini di panggil dari controller pengumuman pada fungsi simpan data pengumuman, dari controller tersebut controller menginputkan data ke dalam database, dengan menggunakan query pada model simpan data pengumuman. Berikut implementasi menu pengumuman dapar di lihat Gambar 11 :

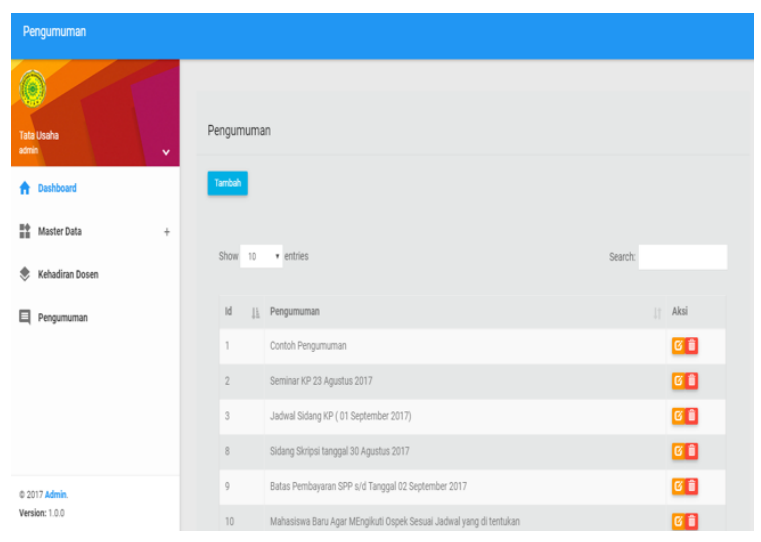

Gambar 11. Implementasi Menu Pengumuman 


\section{KESIMPULAN}

Berdasarkan uraian serta pembahasan sebelumnya, maka dapat ditarik kesimpulan sebagai berikut :

1. Aplikasi sistem informasi deteksi kehadiran dan media penyampaian pengumuman dosen menggunakan teknik pengenalan $Q R$ code dirancang untuk mempermudah mahasiswa untuk memperoleh informasi secara realtime dan dapat diakses secara online.

2. Pemilihan fitur dan perancangan sistem disesuaikan dengan kebutuhan dan kegunaan untuk mendukung kelancaran publikasi informasi oleh bagian tatausaha dan dosen.

3. Menghasilkan sistem yang dapat mendukung kontribusi mahasiswa untuk mengikuti perkuliahan di lingkungan Prodi Teknik Informatika Universitas Muhammadiyah Riau.

\section{DAFTAR PUSTAKA}

[1] Sholeh M Lukman, Muharom Lutfi Ali, "Smart Presensi Menggunakan QR-Code dengan enkripsi vigenere Cipher", Jurnal Limits, Vol 13, No 2, Oktober 2016.

[2] Sutabri, Tata. 2012. Analisis Sistem Informasi. Andi Offset. Jakarta.

[3] Nuddin . M.T, Fithri D.L "Sistem Absensi Asisten Dosen Menggunakan Qr Code Scanner Berbasis Android Pada Program
Studi Sistem Informasi”, Prosiding

SNATIF, ke 2, ISBN : 978-602-

1180-21-1. 2015.

[4] Widianti Utami Dwi, “Pembangunan Sistem Informasi Aset Di PT. Industri Telekomunikasi Indonesia

(Persero)Berbasis Web”, Jurnal Ilmiah Komputer dan Informatika, Volume 1, Nomer 2, Oktober 2012.

[5] Wijaya Adiguna, Gunawan .A, "Penggunaan QR Code Sarana Penyampaian Promosi Dan Informasi Kebun Binatang Berbasis Android”, Jurnal Bianglala Informatika, Volume 4, Nomer 1, Maret 2016.

[6] W.K. Darmawiguna I Gede Mahendra, "Pengembangan Sistem Pendukung Keputusan Kredit Konsumtif Dengan Metode Naive Bayes", Jurnal Nasional Pendidikan Teknik Infomatika, Volume 5, Bomer 3, Desember 2016

[7] W.P. Simaremare Yosua, "Perancangan dan Pembuatan Aplikasi Manajemen Pblikasi Ilmiah Berbasis Online pada Jurnal SISFO”, Jurnal Teknik Pomits, Volume 2, Nomer 3, 2013

[8] Yuhendra. M.T.Dr. Eng, Yulianto Eko Riza. "Rekayasa Perangkat Lunak Pengolahan Data Distribusi Obatobatan Di Pt. Anugrah Pharmindo Lestari Berbasis Web", Jurnal Momentum, Volume 17, Nomer 2, Agustus 2015. 